\title{
Informal STEM education: From Personal to Professional
}

\author{
Jamie Bell \\ Center for Advancement of Informal Science Education (CAISE), Association of Science and Technology Centers, 818 Connecticut Ave. \\ NW, $7^{\text {th }}$ Floor, Washington, DC, 20006 \\ This year marks the $50^{\text {th }}$ anniversary of the founding of the Exploratorium, the self-described "museum of science, art and human \\ perception," in San Francisco, California and the $10^{\text {th }}$ anniversary of the launching of the National Research Council/National Academy of \\ Sciences, Engineering and Medicine report Learning Science in Informal Environments: People, Places and Pursuits. The moment offered \\ me an opportunity to reflect on my own professional journey, which began at the Exploratorium, coincided with a growth spurt of field \\ knowledge-building and has included experiences that inform how I think about the potential and challenges ahead.
}




\section{INTERESTS AND ENTRY POINTS}

1969 was a year of milestones: the moon landing, the first message sent on the ARPANET, the Woodstock Music and Arts Fair, and the Beatles last concert on the roof of Abbey Road studios. I was in 9th grade, attending a small high school in a working class suburb of Pittsburgh, Pennsylvania, where I was an average student more interested in the Beatles than biology class. On the night that Neil Armstrong set foot on the moon, I was in a friend's basement practicing songs from Creedence Clearwater Revival's Bayou Country album, but where we also had one eye on a small black-and- white TV perched on top of a refrigerator where history was being broadcast.

A month after that moon landing, some curious tourists in San Francisco wandered into an open door of the Exploratorium at the Palace of Fine Arts, causing the museum's founder Frank Oppenheimer to remark to a staff member "I guess we're open." (The official Exploratorium opening occurred a few months later in October). That museum of science, art and human perception also just celebrated a 50th year milestone and has since become an iconic model of a research and development lab for informal science learning.

As I played with my band and watched the moon landing that night in 1969 I could have never imagined that I would spend 20 years of my professional career joyfully designing programs, exhibits and activities to engage the museum's visitors and program participants in physical, natural, technological and psychological phenomena.

My rock ' $n$ roll youth led to an appreciation for and an interest in other types of music, including classical, which I majored at Carnegie Mellon University. I performed and taught guitar lessons after graduating and in 1980 moved to the San Francisco Bay Area to teach at a music and arts camp. A CMU classmate and composer had also moved to the area and in 1982 invited me to hear her at a Speaking of Music program at the Exploratorium. Speaking of Music took the form one-on-one interviews with contemporary musicians like John Cage, Laurie Anderson and Brian Eno, who shared excerpts of their music as well as reflections on their influences, processes, and philosophies. So why was the program at the Exploratorium?

In addition to being an accomplished physicist Frank Oppenheimer was an amateur flutist who saw parallels between artistic and scientific inquiry and was interested in making creative processes transparent and accessible for those who were curious. Though I didn't realize it at the time, the program provided me with an entry point to bridging a long held interest with ones I didn't yet know I had.

That said, the night that I attended Speaking of Music in the museum's small theater, I found surrounding exhibits strange and overwhelming. Yet I was intrigued just enough to return for a daytime visit. I was immediately drawn to exhibits that explored and demonstrated sound in ways I had

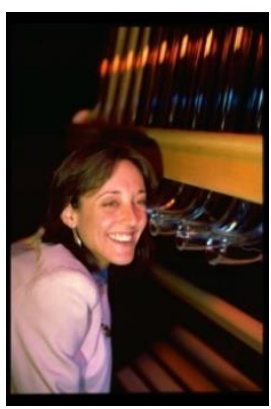

Pipes of Pan

never considered. The simplest of these, one called Pipes of Pan, consisted of ten open-ended glass tubes, each of which resonated at a distinct frequency, determined by its length. Listening to each pipe in turn, from longest to shortest, I heard a strange "scale," emerge from the low to higher pitch tones that were filtering out from the ambient sounds of the museum. It was a creative take on the old trick of listening to a seashell to "hear the ocean," and I was fascinated by its educative, ephemeral simplicity.

In another demonstration of resonance, the "Visible Effects of the Invisible," exhibit lived up to its name by showing what happens in air in such tubes when compression waves reflect off a closed end to create nodes and antinodes of pressure along them. By controlling the pitch and amplitude of tones coming from a speaker at one end, I could see the wavelengths between them when the clear liquid that half-filled the tube sprung little geysers in reaction to the pressure changes in the air above it..

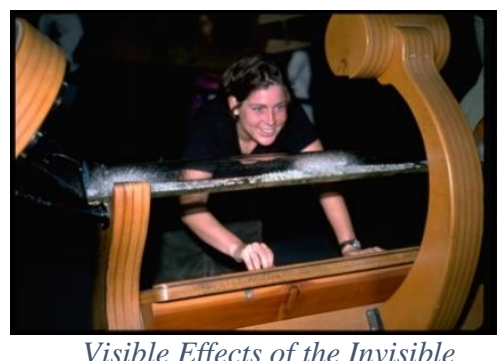

By far the most amazing piece I encountered was an "exhibit," which I put in quotes here to stress how it stretched the limits of my connotation at the time, was the Sound Column, which was actually a 60-ft. high "room" inside one of the Corinthian columns that surround the Palace of Fine Arts. A five-key Gamelan-type instrument was mounted in the center of the room with a large mallet tethered to it. One the museum's high school student "explainers" was on hand to demonstrate how when a particular key was struck, its pitch resonated in the column with nodes and antinodes of pressure that one could experience viscerally by alternately standing and squatting to hear a loud tone 1 at the anti-node or a very soft tone, or none at all at the node. The place has figured out how to put visitors inside a musical instrument, I 
thought! Immersive, direct experiences like these with robust phenomena guaranteed I would be back.

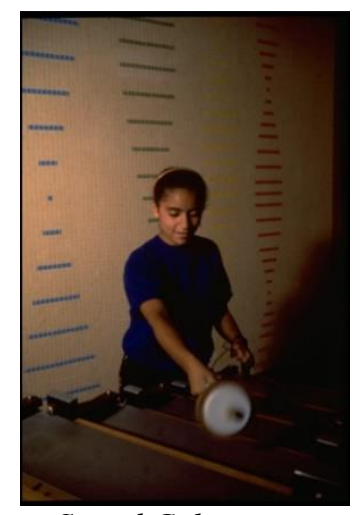

Sound Column

\section{LEARNING AS PARTICIPATION}

So my participation in the Exploratorium began "peripherally," as learning researchers Lave and Wenger might describe it, with visits and when I started volunteering there to see what kinds of deeper opportunities might be available. I soon became aware that the "Morning Explainer" program was recruiting part time adult staff to orient K-12 students on field trips. The program valued teaching experience in any subject, not necessarily science, was looking for those interested in learning and "explaining" concepts using exhibits and demonstrations. Bingo! My curiosity now firmly whetted, and my mornings free from my music teaching and performing schedule I applied for and got the job..

The program's initial and routine training sessions exposed me to a rich variety of physical and perceptual concepts beyond sound and music and more importantly to a diverse group of professionals - scientists, exhibit developers, and artists - who were experts in their subject areas but also approachable people with diverse interests. This was in sharp contrast to my experiences with science in K-12 schooling, where I could not identify with my science teachers, and by extension with the subjects they were teaching. Through the engaging training and my daily experiences on the museum floor with students and teachers, I started trusting my own takeaways from experiences with exhibits and phenomena. Over time I began to have a sense that I could====become someone who can learn and be comfortable with science. In short, while I didn't yet have the words, I was developing a science identity that catalyzed my desire to share what I was learning, and how, with others.

After three seasons of working as a morning explainer, an opportunity to work with the high school explainer program opened up. As a music teacher, high school students had always been my favorites due to the dynamism of their own identity development and the potential of their experiences to shape who they become as adults. By then my comfort level with conceptual physics was augmented by classes I had begun attending at local community city and state colleges.

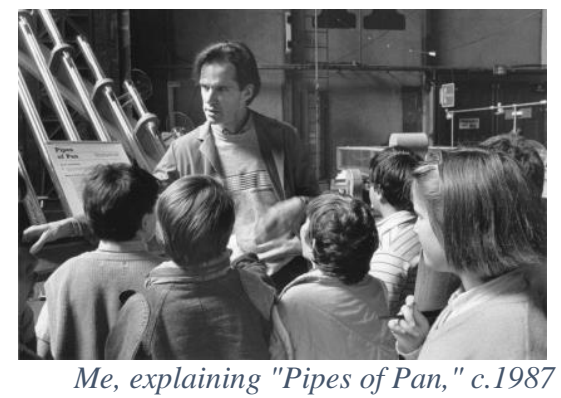

I was also attracted to the new position because of the philosophy behind the explainer program- that teaching is the best way to learn, that high school students were often information-rich but direct experience-poor, and that visitors would appreciate interacting with young people who were excited and challenged by what they were learning on the job. And like the morning field trip program, the practice had been to recruit students with a variety of backgrounds, interests, and academic achievement, and who reflected the ethnic and cultural diversity of the greater Bay Area.

Though I didn't know it then, the high school explainer program was intuitively embodying theories such as situated [1] and sociocultural [2] learning, identity development [3] and constructivism [4]. The years that I spent managing and learning from the program ultimately inspired a plan to apply to graduate school to formally study the education research that I was seeing applied in practice..

\section{KNOWLEDGE-BUILDING}

My decision to return to school coincided with a new direction at the Exploratorium to begin rigorously studying the micro-experiences that visitors were having daily with exhibits. In the mid-1990s a recent Ph.D. from UC Berkeley approached the museum with a funded proposal to conduct research on the Colored Shadows Wall, an exhibit that is now ubiquitous in many science centers. Up to that point developers had mostly iterated their exhibits by putting prototypes on the museum floor and eavesdropping from a respectful distance to see and hear if they were inspiring the kinds of interactions they had intended and designed for. The results of the Colored Shadows Wall study [5] showed that visitors were bringing a wide range of prior learning and assumptions to the experience and that experimenting with strategies for facilitating learning could inform exhibit development for more meaningful engagement. It was the beginning of a new era in knowledge building at the Exploratorium that was also being reflected in the field. 
To wit, this year also marks the 10 year anniversary of the publication of the National Research Council/National Academies of Science, Medicine and Engineering report Learning Science in Informal Environments: People, Places and Pursuits [6]. This consensus study was the first of its kind to compile what was known from the learning sciences about what people are learning in informal environments. By investigating the outcomes of experiences such as the ones described above, the authors identified six strands of science learning that informal environments can foster-interest and excitement about science, understanding of content and models, skills in experimentation, collaboration, ability to reflect on the nature of science, ability to collaborate with others in scientific activities and the development of an identity as someone who can use and contribute to the scientific process.

Over the past decade interest and identity in particular have gained traction as constructs that designers, researchers and evaluators are targeting and studying as learning goals. And it is now clear to me that in the personal and professional trajectory I described above these two factors were key to my own persistence as a science learner and educator. Had my friend not invited me to the Exploratorium one evening in 1982, the uninspiring experience I had with school science would have resulted in a narrower sense of my interests and identity. And had I not had the opportunity to lead the high school explainer program years later I would not have become informed and passionate about how informal setting and experience design has the potential to foster and support the interests and identity development of learners of all ages and backgrounds

\section{FROM THE PERIPHERY TO “THE CENTER"}

Thirty five years after I first walked into the Exploratorium for the Speaking of Music program I am now the Project Director of the Center for the Advancement of Informal Science Education (CAISE), a National Science Foundation (NSF)-funded project based at the Association of Science and Technology Centers (ASTC), the professional association for science museums that formed a few years after the Exploratorium came on the scene. In the time between the membership of ASTC has grown from 20 to over 600 institutions worldwide.

The knowledge building that began with evaluators and researchers like Sue Allen who studied the Colored Shadows Wall is now part of a growing repository of 8000+ reports, articles, instruments and other related resources that can be found on CAISE's InformalScience.org website. Through the support of funding agencies like NSF the field of those who design and assess informal settings and experiences has expanded to include environments and activities where people visit- museums, zoos, aquaria, gardens, parks and nature centers, where people participate, do and makecitizen and community science programs, making and tinkering spaces, robotic competitions and gaming and where people attend, watch, listen, contemplate and interactfestivals, cafes and events, film, TV and YouTube, and radio and podcasts.

The phenomenon of informal STEM learning has variously been defined as free-choice, self-directed, learner-centered and hands-on, or described as lifelong, life-deep and lifewide. There is also now wide recognition that there are cognitive, emotional, social and cultural dimensions to this learning.

\section{OPPORTUNITIES AND CHALLENGES AHEAD}

The NRC/NASEM study mentioned above and others published since have provided informal STEM learning designers with examples and evidence of strategies and approaches for creating activities and settings that address the interests, identity and assets of particular audiences in ways that have resulted in measurable impact. These publications and others from the field of science communication have also pointed out challenges such as the siloed nature of many programs and efforts, inequities of opportunity and access that create underrepresentation, and disconnects between research and practice. Learning Science in Informal Environments was the first to suggest that an ecological framework was helpful for understanding learning across places and pursuits. Since then groups of funders have pooled resources to support "STEM ecosystem" communities of practice in (currently 84) urban, rural and suburban areas across the US [7]. The aim of these ecosystem is to provide infrastructure for connectivity between STEM learning providers- informal and formal- so that learners in these regions will have more opportunities to encounter, engage with and build on their experiences across settings in ways that would have been unfathomable to me as young student.

Funders like the National Science Foundation have committed to addressing the problem of underrepresentation and access with efforts like NSF's Inclusion across the Nation of Communities of Learners of Underrepresented Discoverers in Engineering and Science (INCLUDES) initiative which supports research and the development of a network of higher, formal and informal education institutions and organizations that constitute a community of practice in the areas of diversity, equity, inclusion and access [8].

The Research + Practice Collaboratory [9], a project first funded by NSF in 2012, has been working to support more equitable relationships between research and practice and has developed a series of workshops for building and strengthening research and practice partnerships, and 
resources for STEM educators across the spectrum to use to build relationships that can lead to more relevant questions and more usable results. Other funders such as the W.T. Grant Foundation [10] and the Spencer Foundation [11] are supporting efforts with similar, aligned goals.

With new funding in 2017, CAISE was charged with investigating the current and potential ways in which informal STEM education and the field of science communication share knowledge and goals. Baseline studies confirmed three current areas of common interest and challenge: broadening participation of underrepresented groups in STEM, increasing understanding and use of evaluation and measurement to design for impact and integrating research and practice in ways that advance knowledge building and lead to better project development and design.

In order to explore how to best address these issues CAISE formed task forces consisting of researchers and practitioners from informal STEM education and science communication to research, discuss and share the current state of the field. Task forces in broadening participation, evaluation and measurement and research and practice have been investigating, sharing and discussing what exists and brainstorming and prototyping what kinds of additional tools and supports that a resource center like CAISE can provide to make progress in these areas.

The Broadening Participation Task Force recently launched a toolkit called Broadening Perspectives on Broadening Participation in STEM, which includes a framing report, executive summary for stakeholders, a conversation guide and 11 "practice briefs" that were designed to be conversation starters for staff working in institutions and organizations who want to identify, discuss and address barriers to equitable, inclusive and diverse participation in their programs, activities and offerings. The toolkit takes a critical approach by surfacing topics such as cultural norms in STEM, asset vs. deficit-based approaches, what counts as STEM and rethinking parental engagement.

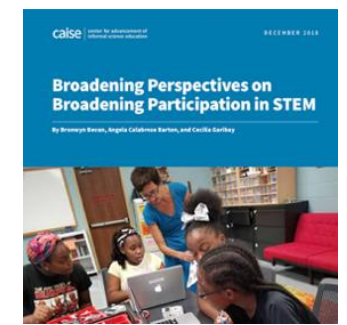

CAISE's Broadening Participation Toolkit

CAISE's Evaluation and Measurement Task Force went through a similar process to identify the need for better understanding of some of the common constructs currently being designed and mediated for in informal STEM learning and science communication environments and activities. STEM identity, interest and engagement emerged as theory- supported concepts that project developers and practitioners often target as learning goals and would like to better understand. The task force conducted a series of video interviews with scholars and experts in these areas and excerpted 3 to 5 minute clips that serve as entry points to their theories, finding and methodologies. Full transcripts of the interviews are linked to on the InformalScience.org website as well as summaries of the high level takeaways from the interviews about each construct.

CAISE's Research and Practice Task Force is currently protoyping a web-based resource for helping researchers and practitioners in informal STEM education and science communication navigate the partnership development process, with resources to access and use at various stages of decision-making along the way. The resource will be launched in April of 2020 on the InformalSCience.org website.

\section{CONCLUDING REFLECTIONS}

Informal science education has grown as a field and made great strides in knowledge-building since iconic science centers such as the Exploratorium opened in the 1960's. My own professional path resulted from and coincided with innovative approaches to reaching audiences who previously had unkindled interests and undeveloped identities in science, technology, engineering and math. That said, the statistics on who participates in the field's many offerings [12], as well as who pursues academic pathways and careers in STEM [13] point out the overrepresentation of dominant groups. Yet every year, as new projects emerge with inclusive, innovative and connective approaches to addressing this problem, they confirm my personal experience that there is limitless potential for us to empower the lives of people of all ages and backgrounds with STEM literacy, knowledge, skills and identity. The half-century-old Exploratorium, where I started my journey, celebrated its $50^{\text {th }}$ anniversary year with an exhibition that speaks to how far the field has come in acknowledging all of what learners bring to designed settings and experiences. Entitled Self Made, the exhibit "is an ethical project to provide visitors with a range of tools to better understand and grapple with the most complicated aspects of identity in our communities and institutions," according to the museum. For the enlightened future of the field, I hope that others will take up a similar charge and build on it.

The views and opinions expressed in this article are those of the author and do not reflect the positions or policies of the National Science Foundation, the Association of Science and Technology Centers or the Center for Advancement of Informal Science Education. 
[1] Lave, J., \& Wenger, E. (1990). Situated Learning: Legitimate Peripheral Participation. Cambridge, UK:

Cambridge University Press.

[2] Vygotsky, L. S. (1980). Mind in society: The development of higher psychological processes. Harvard university press.

[3] Erikson, E. H. (1994). Identity: Youth and crisis (No.

7). WW Norton \& Company.

[4] Piaget, J. (1952). The origins of intelligence in children

(Vol. 8, No. 5, pp. 18-1952). New York: International

Universities Press.

[5] https://www.informalscience.org/using-scientificinquiry-activities-exhibit-explanations

[6] https://www.nap.edu/catalog/12190/learning-science-ininformal-environments-people-places-and-pursuits

[7] https://stemecosystems.org/

[8] https://www.includesnetwork.org/home

[9] http://researchandpractice.org

[10] http://rpp.wtgrantfoundation.org/

[11] https://www.spencer.org/grant types/research-

practice-partnerships

[12] https://www.amacad.org/publication/encountering-

science/section $/ 5$

[13] https://ncses.nsf.gov/pubs/nsf19304/digest 